\title{
Brand-name disease
}

Selling sickness: How the world's biggest pharmaceutical companies are turning us all into patients

Ray Moynihan and Alan Cassels

Vancouver/Toronto: Greystone Books, 2006 254 pp \$32.95 (cloth) ISBN 1-55365-131-6

I n 1999 shyness became a mental illness called social phobia. It wasn't a brand-new diagnosis - the concept had developed over the course of more than 20 years - but now it was on the cover of a US news magazine, in the New York Times and on Good Morning America. Michelle Cottle, an editor at The New Republic, attempted to track the phenomenon and soon learned that SmithKline Beecham (now GlaxoSmithKline) had won FDA approval to market the SSRI antidepressant Paxil as a specific treatment for social phobia. ${ }^{1}$ The drug company had hired a public relations firm that used a subtle ploy, marketing the disease instead of the drug to win the attention of major media outlets.

In Selling Sickness: How the World's Biggest Pharmaceutical Companies are Turning Us All into Patients, Ray Moynihan, an investigative reporter who is a frequent contributor to $B M J$, and Alan Cassels, a drug policy researcher at the University of Victoria, take us behind the scenes of the social phobia marketing campaign, explaining that, "In keeping with modern public relations techniques, the PR firm helped orchestrate what looked like a grassroots movement to raise public awareness about a neglected disorder."

Those looks were deceiving. Although it appeared as if the American

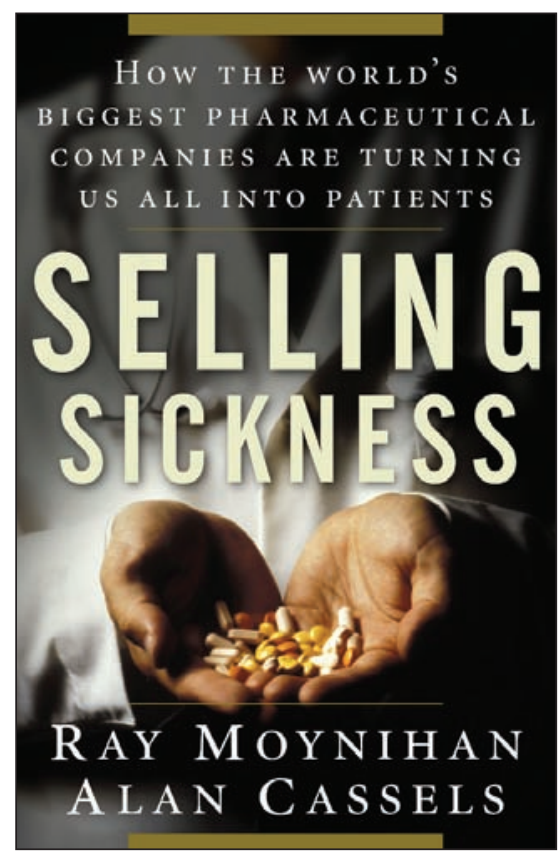

Psychiatric Association and patient advocacy groups such as the Anxiety Disorders Association of America had joined forces to inform the public about an important mental health problem, the social phobia campaign was actually managed, Moynihan and Cassels claim, by Cohn \& Wolfe Healthcare, SmithKline's PR firm. It seems that the strategy was extraordinarily effective. Paxil became the world's best-selling antidepressant, earning US\$3 billion annually. To anyone who's ever wondered why a disorder keeps popping up in headlines or on television, this story is a revelation.

Moynihan and Cassels are at their best when giving us this sort of inside dope about the drug industry's marketing tactics, and they've gathered a lot of it for this book and a related film docu- mentary. Their thesis is that the marketing strategy for Paxil is but one example of a widespread phenomenon in which pharmaceutical companies market diseases, then convince naive consumers that they have the disease and need medication for it. Selling Sickness describes similar efforts surrounding prescriptions for ten medical and psychiatric conditions, including osteoporosis, hypertension and something called female sexual dysfunction. In each case, Moynihan and Cassels spotlight the industry's efforts and then spell out the downside risks. Merck's strategy to increase sales of Fosamax had harmful consequences, they write, because it led doctors to neglect nondrug approaches, such as exercise to decrease the risk of fractures among women with osteoporosis. Manufacturers of calcium-channel blockers encouraged doctors to prescribe that class of antihypertensives, with the result that "collectively the world is wasting billions on the most expensive blood pressure drugs" when cheaper generics would work as well or better.

The notion that illness is shaped or even created by cultural and economic forces isn't new and has been covered by other books reviewed in these pages. ${ }^{2,3}$ However, Selling Sickness stands out for its investigation into the role of the drug industry in this process. At the same time, Moynihan and Cassels can be faulted for tunnel vision. Their unified focus on Big Pharma's marketing techniques, while fascinating, leaves out other crucial factors in the construction of illness, resulting in an account that is at times polemical and overly simplistic. Let's return to so- 
cial phobia for a moment. Selling Sickness leaves the impression that this disorder is almost entirely the result of a PR firm's savvy strategizing. But social phobia is a real phenomenon that deserves a more nuanced account. It was first listed as a disorder in the Diagnostic and Statistical Manual of Mental Disorders in 1980, and by the mid-I99os both the National Institute of Mental Health and drug companies were funding research on it. Epidemiologic studies described people with social phobia as painfully shy, to the point that they had few friends, dropped out of school, didn't work, had trouble dating and didn't marry. Whether or not it qualified as a disorder, people suffered from it and sought help to improve their social skills and quality of life. Then came the FDA's approval of Paxil for social phobia, followed by SmithKline's awareness campaign and the media coverage it generated. Shy people across the US perked up their ears. They had been "listening to Prozac" and the buzz around it but hadn't realized that the new class of antidepressants might help them, too.

Moynihan and Cassels describe one such individual, an unemployed California woman named Deborah who was nervous about job interviews. After seeing a commercial on television that described social anxiety disorder and mentioned Paxil, she went to the doctor, got a prescription and landed a job in real estate that she held for four years. "I think taking the medication helped me be able to work with the public in a comfortable way," she said. She was pleased until she experienced Paxil's difficult withdrawal syndrome - a problem that neither doctors nor patients were aware of initially. (In 2002 the FDA issued a warning that Paxil can cause severe withdrawal symptoms.)

In their zeal to drive home their message, Moynihan and Cassels mock Deborah's difficulties and her reliance on an antidepressant. "With her successful self-diagnosis of social anxiety disorder," they write, "Deborah was at the frontier of medical science - her condition had only just been pushed from the shadows of obscurity into the glare of the public spotlight, and the powerful antidepressant Paxil had just become the first drug ever approved to treat it."

The authors are equally derisive in their description of Murray Stein, a psychiatrist who began studying social phobia while at the University of Manitoba in the early I9gos and later ran clinical trials testing the effectiveness of Paxil and other drugs for the disorder. Stein also wrote a popular book that lists exercises to help people overcome shyness, but in the hands of Moynihan and Cassels he's little more than a mouthpiece for SmithKline, because he ran company-sponsored trials and "offered flattering praise for Paxil" in company press releases.

Moynihan and Cassels have amassed a wealth of information, and their writing is entertaining and easy to follow, but they might have achieved more if they had been willing to look beyond Big Pharma. The reasons people take drugs - prescription or other-

\section{Room for a view}

\section{Come, let's to bed}

\author{
Come, let's to bed, \\ Says Sleepy-head; \\ Tarry a while, says Slow: \\ Put on the pan, \\ Says Greedy Nan, \\ Let's sup before we go.

\section{- Traditional nursery rhyme}

I was brought up in an English boarding school whose attitudes and initiations were dedicated to "muscular Christianity" and the principle that early to bed and early to rise would make a man healthy, wealthy and wise. Somewhat later, when I was at medical school, I was exposed to Professor R.S. Illingworth's idea that it was unnecessary and usually futile to attempt to keep recuperating children in bed. But it was the physician ond essayist Richard Asher who really spilled the beans about the malevolent E effects of bedrest with an article in a în 1947 issue of the British Medical Journal. "Look at a patient lying long in ठे bed," he writes. "What a pathetic pic- wise - are complex and not easily boiled down. In a recent issue of Salon, David Amdsen speculates on the current popularity of SSRIs and psychostimulants and concludes that they are being used as performance-enhancing substances. It's an outlandish suggestion that involves doctors and patients as much or more than drug companies, and he just could be right.

\section{Miriam Shuchman}

Department of Psychiatry

State University of New York

Buffalo, NY

\section{REFERENCES}

I. Michelle C. Selling shyness. How doctors and drug companies created the "social phobia" epidemic. New Repub i999; (Aug 2):22-9.

2. Deshauer D. Disease as idea [book review]. CMAJ 2005;I73(7):790-I.

3. Garland E J. Bitter pills [book review]. CMAJ 2004;I7I(II):I374-5.

4. Amsden D. Life: the disorder. Salon 2005; Nov 25. Available: www.salon.com (accessed 2006 Feb 20).

ture he makes of blood clotting in his veins, the lime draining from his bones, the scybala stacking up in his colon, the flesh rotting from his seat, the urine leaking from his distended bladder and the spirit evaporating from his soul. ${ }^{1}$ Is it not surprising, therefore, that for many years I was of the opinion that time spent on a palliasse was a waste." This attitude predominated for several years, to the point where I briefly considered taking up jogging.

Providentially, I mentioned this mental aberration to another expatriate, who jogged the memory of a talk given by Cecil Woodham-Smith on the $\mathrm{BBC}$ sometime in the late I950s. Although both of us remembered his account with pleasure, it was my discerning colleague who called attention to the crucial message.

Woodham-Smith had imparted the information that certain resolved men and women whose accomplishments were renowned had in fact spent the 